Research Article

\title{
Comprehensive Indicator Bank for Resilience of Water Supply Systems
}

\author{
Mostafa Baghersad $\left(\mathbb{D},{ }^{1}\right.$ Suzanne Wilkinson $\mathbb{D D}^{2}$ and Hamed Khatibi $\mathbb{i D}^{1}$ \\ ${ }^{1}$ Department of Civil and Environmental Engineering, The University of Auckland, Auckland 1010, New Zealand \\ ${ }^{2}$ School of Built Environment, College of Science, Massey University, Auckland 0632, New Zealand \\ Correspondence should be addressed to Mostafa Baghersad; m.baghersad@auckland.ac.nz
}

Received 12 July 2021; Revised 22 November 2021; Accepted 8 December 2021; Published 24 December 2021

Academic Editor: Hélder Sousa

Copyright ( $) 2021$ Mostafa Baghersad et al. This is an open access article distributed under the Creative Commons Attribution License, which permits unrestricted use, distribution, and reproduction in any medium, provided the original work is properly cited.

\begin{abstract}
Appropriate indicators are required to measure the resilience of water supply systems (WSSs). However, it is challenging to identify appropriate indicators since there is no comprehensive database of indicators to measure its resiliency. This study will establish a comprehensive bank of indicators to assist water corporations and decision-makers in selecting appropriate indicators for their particular system. The suggested indicator bank is comprised of three layers such as dimension, attributes, and the number of indicators resulting from 12 different indicator codes that the study has analysed. In addition, this paper presents instructions on how the indicator bank can be used and integrated with water enterprises, enabling decision-makers to pick the relevant indicators. The proposed indicator bank is an exploratory approach that should be validated in a real work setting since resilience is a challenging concept, and WSSs are complex due to their dependencies to other lifelines such as power networks with too many variables that may affect the actual outcomes.
\end{abstract}

\section{Introduction}

The most recent "Sendai Framework for Disaster Risk Reduction (SFDRR)" agreement was developed to minimise disaster mortality, the number of people affected, and economic losses throughout the world. SFDRR regulates the risk to critical infrastructures (such as WSSs) and the disruption of essential services caused by natural disasters [1].

Lifelines such as water supply systems (WSSs) are potentially vulnerable to natural disasters due to the widespread use of their components. The total performance of a water system is determined by the performance of each element including supply, storage, transmission, distribution, and the system as a whole. Previous earthquakes such as Northridge in California (1994), Kobe in Japan (1995), Bam in Iran (2003), L'Aquila earthquake (2009) in Italy, Haiti (2010), Tohoku in Japan (2011), Christchurch in New Zealand (2011), and Gorkha in Nepal (2015) showed how communities could be affected by water system disruption due to an external shock. For example, about $80 \%$ of residents lost their water supplies in New Zealand after the earthquake in Christchurch in February 2011 [2, 3]. Meanwhile, the Haiti earthquake in 2010 demonstrated how difficult it was to provide sufficient water, both in terms of quality and quantity, in the aftermath of the tragedy. The Haiti earthquake triggered a series of breaks in the main water supply, closing off its sources to the people for two weeks $[4,5]$. According to Ballantyne and Crouse [6], the Northridge earthquake affected 1,500 pipeline networks in Los Angeles, while the Kobe earthquake caused 1,600 breakdowns in the city's water distribution system.

Risk analysis has historically been used as an ideal method to understand the water system's performance in a particular situation [4]. However, there are several limitations to using this method. This method is only appropriate to estimate the component level of the system, and it is beneficial for situations where the system's overall performance estimation is minimal [7]. Another limitation is that the risk analysis method frequently neglects to consider the system's performance over time [4]. Critical infrastructure networks such as WSSs are instances of complications characterised by data excess in large-scale risk assessments. 
Recent advances in information technology such as SCADA (Supervisory Control and Data Acquisition) for water systems, along with increased concern in estimating and controlling large-scale functionality, need the explorations of alternative approaches [8].

Meanwhile, the resilience concept is developed to measure the whole system's performance by considering the element of time. Consequently, the idea of disaster resilience has acquired wide attention. It has become more common, particularly following the adaptation of the "Hyogo Framework for Action 2005-2015: Building the resilience of nations and communities to disasters" [9, 10]. However, resilience is a comparatively new concept in the disaster management field that acknowledges the need to minimise disaster disruption to help emergency management programmes [11].

Holling [12] first applied the concept of resilience to the field of ecology, conceptualising the term as "the measure of the persistence of systems and their ability to absorb change and disturbance and adapting their internal dynamics if needed." Scholars later enriched its concept in a wide variety of fields such as socio-ecological $[13,14]$, geography $[15,16]$, psychological [17], urban planning [18, 19], supply-chain management [20], and engineering [21, 22]. Each of these fields has a distinct perspective on resilience. In ecology, resilience is a strategy for learning more about the complexity of an ecological system's reaction to internal and external stimuli that threaten its functionality. However, resilience is more treated as beneficial goal status in anthropogenic environments (like infrastructure systems or communities) [23]. While community disaster resilience is a significant study subject in disaster resilience $[24,25]$, it defines resilience as a concept that "enhances the ability of a community to prepare, absorb, recover, and more successfully adapt to actual or potential adverse events in a timely and efficient manner" [11].

Measuring community resilience to disasters across time and specific cases remains a challenge for scholars and practitioners [26]. The most widely used metrics for describing systems resilience is performance or functionality. In general, these terms are used interchangeably to represent how a system losses its ability to function after a disaster and how it is restored over time [27].

A rising number of academics from several areas are focusing on developing indicators to assess the resilience of their systems. An indicator-based approach to mitigate and manage the risk of disasters within communities was introduced by Hahn [28]. It focuses on the creation of a set of indicators to select suitable disaster resilience indicators. The "Baseline Resilience Indicators for Communities (BRIC)" suggested by Cutter et al. [29] is widely used and includes a range of secondary indicators to measure community resilience [30]. The study of Martins et al. [31] on assessing the resilience of the urban mobility system, the study of DasGupta and Shaw [32] on assessing the resilience of coastal community against climate change, and work of Jovanović et al. [33] on the resilience of smart critical infrastructures are some examples of an indicator-based approach for measuring the performance of resilience.
A study of the literature on WSSs' resilience reveals considerable attempts to build an indicator system to measure its performance. Morley [34] employed an indicator-based model in water utilities and identified two operational and financial indicators. It utilised the "Utility Resiliency Index" to assess the resilience of WSSs. Baki et al. [35] proposed a modelling approach that assesses alternative interventions to urban water systems (UWSs) under a set of performance and resilience indicators. Nikolopoulos et al. [36] proposed a novel technique for assessing resilience in real-world WSSs.

A framework was developed by Balaei et al. [37] to measure water supply resilience, with an emphasis on the significance of community features to resilience. It based its indicators on four dimensions proposed by Bruneau et al. [22], namely, organisational, social, economic, and technical [4, 38-40]. However, the environmental dimension is considered less significant despite being an essential feature of resilience, and the proposed framework only is applicable to earthquake-prone areas and developed countries. More recently, Sweya et al. [41] added an environmental dimension to their tool to measure the resilience of WSSs [42] to the four dimensions mentioned above [43-45]. This tool was developed in case of floods in Tanzania.

Throughout the previous few decades, several indicator lists have been produced by organisations and scholars in favour of decision-makers for the resilience of WSSs. The choice of the most suitable collection of indicators has long been an interesting topic but one that has also caused misunderstanding and impeded the efforts of the decision-makers for monitoring the resiliency projects since the selected indicators are varied. Moreover, the selected indicators are usually developed in their specific system and circumstance and, therefore, purposefully chosen to follow its predetermined policy goals. By considering the recent city developments and interaction of WSSs with other lifelines such as power systems, resilience assessment tasks have become more complicated. Therefore, the water companies have to create their own indicator set from scratch by means of several workshops. The question is whether the current collection of indicators is adequate for assessing the resilience of WSSs. Is there a comprehensive indicator bank that companies can use to choose appropriate indications and easily modify them to their systems?

This paper aims to propose a comprehensive indicator bank emphasising the resilience of WSSs. To achieve the research goal, a set of indicator codes is collected to explore and identify the design approach of each indicator code. A pool of indicators was utilised to extract the suitable indicators. The obtained indicators are analysed and categorised based on a structured indicators system proposed by reviewing the indicator codes. Moreover, a framework is presented as a way of using the proposed indicator bank in order to select appropriate indicators. The results of this study may help scholars or water companies access a comprehensive indicator bank to fulfil their system's resilience objective and strategy.

\section{Methods}

The research uses a qualitative approach to data gathering, analysis of the data, and interpretation because of the objective of the research and combination of technical, 
economic, ecological, and social nature of WSSs. A qualitative approach, including systematic analysis of publications, standards, reports, and documents henceforth referred to as "codes," was utilised to understand the concept of resilience and its dimensions in the context of WSSs. To establish the crucial attributes that help grasp and characterise the notion of resilience and its relationship to WSSs, the concept analysis approach [46] was utilised. This entailed looking for the cluster of attributes that were most frequently linked to the recognised dimensions. This review was continued by looking at indicators (measures) that influence system resilience and have the potential to inform the systems' ability to withstand the effects of natural disasters.

The method is applied through five-step processes in attaining the study aim. Steps of the method used to propose a comprehensive indicator bank for the resilience of WSSs are presented in Figure 1, with more information in the subsequent sections. The method applied in this research was adapted from the study by Von Thenen et al. [47], which created an indicator pool in marine spatial planning and from the study by Khatibi et al. $[48,49]$ and Stratigea et al. [50], which proposed an indicator bank for smart, resilience, and sustainable cities.

The selection of various codes and sets of indicators is the first step in achieving the research's aim. The most detailed analysis of indicators for WSS that has been carried out to date is the "City Water Resilience Approach (CWRA)," provided by Arup and Siwi [51]. The CWRA provides a set of indicators classified into four dimensions, including leadership and strategy, planning and finance, infrastructure and ecosystems, and health and wellbeing, which provides good starting points for collecting the indicators for technical, organisational, social, and economic dimensions recognised by Bruneau et al. [22] and environmental dimension proposed by Sweya and Wilkinson [42]. After a literature review, 12 different indicator codes have been selected in this step based on the high citation, diversity in the codes' geographical scale, and considering the whole system instead of one component.

The selected indicator codes are reviewed in the second step, and each individual indicator is identified and analysed. Reviewing the indicator codes revealed that the indicators are grouped differently. For example, the City Water Resilience Approach (CWRA) is made up of three rings that provide a holistic model for city water resilience: dimensions, goals, and subgoals. The proposed system includes 53 subgoals grouped into 12 primary goals, while these topics are further aggregated into four dimensions. These rings are referred to as layers in this study. For example, dimensions are the first layer, goals are the second layer, and subgoals are the third layer. Such a framework describes a holistic city water resilience model, which refers to this study as a conceptual design. The conceptual design of the indicator codes varies. Some codes, for example, utilised two layers, whereas others used three or four layers. Furthermore, the terminology used to describe the layers differs in the selected indicator codes. For example, the first layer is referred to as dimensions and domains, while the second layer is referred to as goals, attributes, principles, and measures. As a result, all indicators were gathered in a spreadsheet and reviewed based on their conceptual design.

The third step is creating a pool of indicators, in which all indicators are drawn to the pool. Some types of adjustments are made in this step. Removal of indicators occurs when the indicators are duplicated or the indicators are not specific to WSSs. Some indicators are split when the indicators include several indices from various dimensions. Some indicators are merged when indicators can be categorised as an indicator.

The next move is to establish and structure an indicator framework based on current global performance indicators that would be more broadly applicable for assessing the WSSs' resiliency in a more structured and coherent manner. The outcome of step 2 has been used to form the proposed structure.

The final step is proposing the comprehensive indicator bank based on the structured system developed in the previous step. All indicators extracted from the pool are analysed and categorised according to the structured system in this step.

\section{Selection of Water Resilience Indicator Codes}

Throughout the years, several organisations, consisting of international, national, and nongovernmental organisations (NGOs), and independent scholars, have proposed resilience indicators for water systems through tools and frameworks to measure the performance of water systems, as discussed below.

For example, in the Netherlands, the Delft Hydraulics Laboratory suggested a procedure to assess the water supply initiative's contribution to sustainability [52]. It resulted in a mixture of indexes, each subdivided into subcriteria, covering five criteria. Five years after that research, Loucks [53] emphasised calculating the relative sustainability of renewable WSSs. A weighted combination of three measures, including reliability, resilience, and vulnerability, is used to provide an index for measuring different environmental, social, economic, and ecological dimensions.

Meanwhile, Sullivan [54] suggested a "Water Poverty Index (WPI)" that assesses the connection between poverty and WSSs. This research concluded that it would be possible to pursue a rational approach to water allocation by connecting physical and social science to resolve the problem.

De Carvalho et al. [55] introduced a systematic approach to establishing a "Sustainability Index for Integrated Urban Water Management (SIUWM)" that could be used to assess the sustainability capacity of a city. This index consists of five items that are split into 20 measures and finally into 64 variables. Results from SIUWM applications show that the index will emphasise enhancing and ultimately guide effective action and policymaking to better delivery of services and better management of resources.

Gonzales and Ajami [56] developed a regional integrative framework for evaluating the sustainability of water resources and identifying sustainability opportunities. In this research, a numerical index composed of supply, demand, and adaptive capability metrics was developed to 


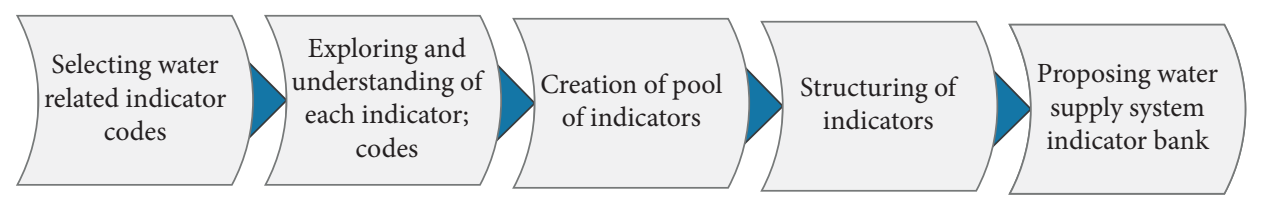

FIgUre 1: Proposed steps to create the comprehensive indicator bank of WSSs.

quantify sustainability. According to the research findings, water authorities are in an excellent position to establish integrative regional management cooperation in order to realise individual and mutual short-term and long-term advantages.

The "Environmental Protection Agency" (EPA) of the United States concentrated on the resilience of the water distribution system to natural and man-made disasters. In this research, potential resilience indicators such as topological reliability, hydraulic reliability, and entropy reliability were used to quantify the performance of the water distribution system. However, none of the indicators provided in this report has been validated against disasters. More research is suggested to develop realistic system measurements to assess the system's resilience and incorporate water distribution system technologies [57].

Alegre and Parena [58] proposed performance indicators for water supply services. The primary goal of this manual is to give guidance for developing a management tool for water supply enterprises based on performance indicators. Performance indicators are used to evaluate the efficiency and effectiveness of a WSS [59, 60]. This manual was used in various water supply projects across the world, mainly in Europe, including Austria and Germany, for benchmarking $[60,61]$. The overall concept of this manual was built on a layered pyramid structure, beginning with raw data at the bottom and feeding the performance indicators on the higher layers. This framework is made up of a theme of indicators, subindicators, and variables. The performance indicators are classified into six categories: water resources, human, physical, operational, quality of service, and economic and financial $[58,60]$. However, as indicated in the manual, the system offers performance indicators that may be relevant at the top management level of a water supply project, and it seeks to include necessary factors required to explain management objectives and outcomes in terms of an organization's performance. Complementary indicators will be required at the departmental level although they are considerably more organisation dependent [58].

The "Swedish Water and Wastewater Association (SWWA)" recently developed the "Swedish Sustainability Index for Municipal Water and Wastewater Services" to give a complete picture of water and wastewater sustainability as a technique for study on short-term and longterm decision-making. This tool prioritises activities and resources, tracks improvement, and proposes a framework for strategic planning and analysis of the city's requirements. Unlike many other indices, this tool is not aimed at contrasting municipalities but presents municipalities with their outcomes to create a robust and context solution for water and wastewater management [62]. However, the publication is available to the region only, and the indicators cannot be replicated.

The "SDEWES City Index" was created as a benchmarking tool for cities by the "International Centre for Sustainable Development of Energy, Water, and Environment Systems (SDEWES Centre)." It assesses the long-term production of energy, water, and environmental processes using an integrated methodology to promote policy learning, action, and collaboration in cities worldwide for longterm growth. The tool is developed based on seven dimensions, 35 indicators, and around 25 subindicators. This index is currently implemented in 120 cities worldwide based on various parameters for increasing spatial diversity. Apart from focusing on many aspects of sustainable growth, the index also provides water quality indices, emphasising drinking water quality. These metrics are provided within the "Water Usage and Environmental Quality" dimension $[63,64]$.

In light of the foregoing, this research study focuses on worldwide views in order to assess applicable codes and frameworks linked to the water supply system's resilience to natural disasters. The following reasons contributed to the selection of codes and the filtering process. First is the number of citations; high citation codes are considered to have a higher impact and, therefore, are more reliable. Second is diversity in selected codes; this study proposes a comprehensive indicator bank to apply worldwide. It considered the diversity in the geographical selection of codes and the scale of the proposed codes (international, national, and so forth). Finally, instead of focusing on one single component such as reservoirs, the chosen indicators codes considered WSSs as a whole system. The filter process resulted in 12 codes applicable to measure the WSSs' resilience, shown in Table 1.

\section{Analysing of Each Indicator Code}

The analysis of indicator codes follows a detailed exploration of 12 selected standards, publications, and documents in the previous step. A similar process is replicated for each code to understand its conceptual design, as discussed in the following subsections.

4.1. Canadian Water Sustainability Index (CWSI). The "Canadian Water Sustainability Index (CWSI)" was established by Canada's "Policy Research Initiative (PRI)" in reference to the "Water Poverty Index (WPI). " It aims to incorporate the environmental, physical, and socio-economic dimensions of water essential to Canadians and the 
TABLE 1: List of selected codes.

\begin{tabular}{|c|c|c|c|c|}
\hline Code & Author/institution & Name & Scale & Reference \\
\hline 1 & $\begin{array}{l}\text { Policy Research Initiative (PRI) project } \\
\text { sustainable development }\end{array}$ & Canadian Water Sustainability Index (CWSI) & National & {$[65]$} \\
\hline 2 & Hatem M. M. Ali & Arab Water Sustainability Index (AWSI) & National & {$[66]$} \\
\hline 3 & $\begin{array}{c}\text { "KWR Watercycle Research Institute" } \\
\text { and Netwerc } \mathrm{H}_{2} \mathrm{O}\end{array}$ & City Blueprint & $\begin{array}{l}\text { International (mostly } \\
\text { in Europe) }\end{array}$ & {$[67]$} \\
\hline 4 & $\begin{array}{l}\text { NZ Transport Agency (research report } \\
\text { 546)/AECOM New Zealand Ltd }\end{array}$ & $\begin{array}{l}\text { Measuring the resilience of transport infrastructure } \\
\text { (NZTA) }\end{array}$ & International & {$[68]$} \\
\hline 5 & ARUP and Sydney Water & $\begin{array}{l}\text { The Future of Urban Water: Scenarios for Urban } \\
\text { Water Utilities in } 2040 \text { (FUW) }\end{array}$ & National (Sydney) & [69] \\
\hline 6 & $\begin{array}{l}\text { The Cooperative Research Centre for } \\
\text { Water-Sensitive Cities (CRCWSC) }\end{array}$ & Water-Sensitive Cities Index (WSC Index) & International & [70] \\
\hline 7 & ARUP and Welsh Water & Welsh Water Resilience & National UK & {$[71]$} \\
\hline 8 & ARCADIS & Sustainable Cities Water Index (SCWI) & International & {$[72]$} \\
\hline 9 & Maiolo \& Pantusa & $\begin{array}{l}\text { Sustainable Water Management Index } \\
\text { (SWaM_Index) }\end{array}$ & National & [73] \\
\hline 10 & ARUP \& SIWI & The City Water Resilience Approach (CWRA) & International & {$[51]$} \\
\hline 11 & Balaei & $\begin{array}{c}\text { Multidimensional factors affecting water supply } \\
\text { resilience }\end{array}$ & International & {$[3]$} \\
\hline 12 & Sweya & $\begin{array}{l}\text { Development of a tool to measure resilience against } \\
\text { floods for water supply systems in Tanzania }\end{array}$ & National Tanzania & {$[74]$} \\
\hline
\end{tabular}

region's natural circumstances. The PRI has built and validated a composite water index to assess Canadian communities' wellbeing concerning freshwater. This index incorporates various water-related data and knowledge in different indicators. Together, the measures provide an integrative profile of critical water problems in the region and enable intracommunity and intercommunity comparison and analysis. The fifteen indicators are equally divided into five policy-based components: resource, ecosystem health, infrastructure, human health and wellbeing, and capacity. The higher the CWSI score for the environment, the better equipped it is to enjoy and preserve freshwater's ecological, socio-economic, and health benefits. The CWSI was fieldtested in six group case studies (PRI, 2007).

4.2. Arab Water Sustainability Index (AWSI). The "Arab Water Sustainability Index" (AWSI) is a conceptual framework that integrates several water status elements in the Arab countries; physical, social-economic, and environmental. Meanwhile, four theme-based components have been suggested for the AWSI to represent a valuable and practical breakdown: dependency, shortage of water, the sustainability of the environment, and water volume. This index is a sustainability tool that evaluates the baseline condition or duration, allowing regions to be compared with one another or over time. The AWSI is based on eight indicators and 22 variables. A mathematical aggregation is applied to condense variables into a manageable data set, further simplified into an index [66].

4.3. City Blueprint. The City Blueprint project is headed by the "KWR Watercycle Research Institute" and "Netwer$\mathrm{cH} 2 \mathrm{O}$ " and includes a wide variety of information providers, institutional bodies, networks, and regional authorities to establish it. The City Blueprint approach is a tool that comprises three frameworks: the "Trends and Pressures Framework (TPF)" is used to analyse the major urban issues; the "City Blueprint Framework (CBF)" governs how cities manage their water cycles; and the "Governance Capacity Framework (GCF)" is used to identify areas where cities may enhance their water governance [75].

The CBF is a tool that is used in municipalities to determine the total sustainability of "Integrated Water Resources Management (IWRM).” It offers a quick scan and baseline review of urban water systems and is developed to compare the IWRM of cities and promote the sharing of success stories between cities to overcome the urban water problems [67]. The assessments have been conducted and are available for more than 70 municipalities and regions around 40 countries. However, it is established mainly in Europe, focusing on the water framework, wastewater, and climate adaptation in the cities [75]. The metrics were subdivided into eight broad groups: water security, water surface quality, and groundwater, sanitation, drinking water, infrastructure, environmental stability, biodiversity, attractiveness, and governance. It runs through a questionnaire that records the radar diagram's responses, including the Blue City Index. The Blue City Index is a mean value of 24 measures ranging from zero (concern) to ten (no concern). The City Blueprint outlines the cities' strengths and weaknesses and takes the first step in the long-term plan for communities [67].

4.4. NZ Transport Agency. The "New Zealand Transport Agency" hired AECOM to create a methodology for assessing the resilience of New Zealand's transportation infrastructure. Its design is relevant to the whole land transport system (road and rail) and considers multiple sizes (asset/network/region). The partnerships developed an assessment tool that encompasses resilience's technical and organisational dimensions into specific concepts and metrics 
to assess resilience qualitatively. They developed three concepts of technical dimensions hinging on robustness, redundancy, and safe-to-fail, while organisational aspects addressed preparation for the transition, networks, leadership, and culture (Hughes and Healy, 2014).

Although the transportation system's functionality is different from water supply systems, both are critical lifeline networks, and the proposed indicators can be adapted to WSSs. As a result, this code was reviewed with other water-related codes to create the suggested indicator bank for this study.

4.5. The Future of Urban Water (FUW). The "Future of Urban Water" is a publication that resulted from a cofunded partnership between the international engineering group Arup and Sydney Water experts. The project discussed the development and potential scenarios for the future of the urban water system in 2040. The scenarios were based on theoretical assumptions, which made it easier to recognise and evaluate different futures under precisely specified conditions. The premises include developing the economy, increasing the population of cities, climate change, increasing water resources volatility, utility management efficiency, and utilising smart services. The research assessed over 100 social, environmental, political, and technical indicators based on four main scenarios that will direct Sydney Water's long-term planning [69].

4.6. The Water-Sensitive Cities Index (WSC Index). The WSC provides an index using a tool to benchmark cities' current performance according to the water-sensitive objectives. The WSC goals are developed to improve effective water policy, population involvement, equity of essential services, production and resources efficiency, urban space quality, ecological health, and sustainable infrastructure. The goals are divided into 34 indicators. In a collective workshop phase, each of the 34 metrics is rated on a scale of 1 to 5 [76]. The information is then entered into a web-based application that will sort the outcomes based on the most beneficial user. The index was developed in the preliminary phase by two local governments in Melbourne and a Perth pilot test. The tool is now being used by various water companies and local governments and launched through a partnership with Asian Development Bank in five Asia-Pacific cities [70, 77].

4.7. Welsh Water Resilience Framework and Strategy. Welsh Water was one of the first companies in the UK to conduct a comprehensive review of its system's resilience. The company built its resilience wheel early in 2017, which underpin its long-term plan in 2050. This wheel is used as a resilience framework to define their strong points and areas of development. A long list of shocks and stresses and the possible impact on organisations was created by the University of Cardiff's collaboration. Therefore, Welsh Water has explicit knowledge of the risks imposed by many shortterm disasters with working in conjunction with Arup and Cardiff University. The company also undertook the horizon-scanning study to learn how short-term disasters will change and affect the company in the long term [78]. Later, the Water Services Regulation Authority of England and Wales (Ofwat) released "Resilience in the Round" [79], which emphasised guidance for businesses dealing with resilience issues. Following this publication, Arup created a framework for assessing the corporate, operational, and financial aspects of a company's resiliency. It also prompted Welsh Water to update its Resilience Wheel, which is comparable to the "Round in Resilience." To conform with current regulatory standards, the appraisal created a modification to the Welsh Water Resilience Wheels. Finally, the wheel is created using a system-level approach, which is divided into three key components: finance and governance, technology and environment, and people [71].

4.8. Sustainable Cities Water Index (SCWI). In conjunction with the "Center for Economics and Business Research (CEBR)," the ACRADIS "Sustainable Cities Water Index" analyses three aspects of robustness (resilience), productivity (efficiency), and safety (quality) waterscapes to produce an indicative ranking of 50 leading cities. The index inspected the water sustainability of 50 urban communities from 31 nations. According to the survey, the 31 communities examined require more investment to endure natural calamities and water shortages. Meanwhile, climate change adaptation and resilience are becoming the most pressing problem for aspiring city leaders in the future. The index reveals which city is better at managing and controlling water-related issues in the long term. The findings call for more significant expenditure to boost the city's response to adverse weather conditions and unexpected water scarcity. The city authorities need to pay careful attention to each area of water sustainability to ensure long-term stability [72].

\subsection{Sustainable Water Management Index (SWaM_Index).} The SWaM_Index bases its measurements on economic, environmental, social, and institutional indicators and is ideal for different administrations in the field. The indicators are aggregated into subthemes, topics, and pillars organised through hierarchical relationships, while the synthetic index is calculated using proper clustering techniques. The management of water resources is viewed in terms of natural (different types of natural), artificial structures (set up for the management of natural resources), and environmental and socio-economic aspects. The SWaM_Index arranges Artificial Systems (AS), Natural Systems (NS), and Socio-Economic-Institutional Systems (SEI) as three pillars representing its sustainable components. It is then subdivided into themes, which further divides into subthemes, and finally into elementary indicators for each subtheme. The water supply system is identified as a theme in the artificial system pillar with two subthemes such as service availability and service management and 29 indicators [73].

4.10. The City Water Resilience Approach (CWRA). The "City Water Resilience Approach (CWRA)" responds to the need for creative approaches and tools to help cities develop urban 
water resilience. The CWRA invention focuses on cities' ability to ensure high-quality water supplies for their citizens, avoid water-related risks, and connect them through water-based networks. The approach benefits from field research and desk analysis, collaborations with authorities on the subject, and direct interaction with stakeholders in the community. The CWRA defines a framework for improving urban water resilience and offers resources to help communities improve their resiliency in the face of shocks and stresses related to water. The strategy includes five processes to guide cities including initial stakeholder participation, baseline evaluation, action planning, implementation, and monitoring of new measures that enhance water resilience. The framework is finalised to four dimensions, 12 targets, and subgoals to achieve these directives [51].

4.11. Balaei's Research on Multidimensional Factors. This research proposed a framework for assessing the WSSs' multifaceted resiliency based on the relevance of various communities' characteristics [8]. The suggested framework (CARE) comprises eight core phases: developing conceptual framework, choosing suitable indicators, optimising indicators based on data availability, correlation analysis, escalating indicators, the weighting of variables, measuring, and aggregating the indicators. This framework highlighted the essential technological, social, institutional, and economic variables and metrics to assess these dimensions. Factors and metrics have been collected, and it is validated and ranked via a series of interviews with the water supply and resilience experts, social scientists, and economists. Technical factors were evaluated in selected earthquake scenarios in Pukerua Bay in New Zealand, while the social factors were also tested across New Zealand and Chili. The organisational and economic variables were measured after the Christchurch earthquake in New Zealand in 2011 [3]. Although the framework is tested in different cases in a real or hypothetical case, the indicators are developed only for earthquakes.

4.12. Sweya's Study to Develop a Measurement Tool for Tanzania. A multidimensional tool was developed for Tanzania's water supply system by Sweya [74] to measure their systems' resilience. The research employed expert's judgment across five phases, including preassessment of variables, pretesting of variables, creating the tool via the Delphi study, the final assessment, and validation of the tool. The tool has five dimensions, discussing the water supply systems' numerous resilience problems: technological, institutional, social, economic, and environmental. Overall, 47 indicators have been proposed in different dimensions to show the system's existing resiliency level when tested in selected Tanzanian water supply systems and indicate the aspect that needs improvement. The instrument contributes to a reliable water supply during flooding and minimises global temperatures to meet the Paris Agreement [41, 74]. The instrument was, however, designed for developing countries and only in the event of flood events.
4.13. Conceptual Design of Selected Codes. The selected codes were reviewed in detail, and the conceptual design of each indicator code is analysed and summarised in Figure 2. The analysis of these conceptual designs has been used to feed step four (refer to Figure 1) to build the structure of the indicators.

\section{Creation and Outcome of the Pool of Indicators}

A bank of indicators is proposed from a pool of indicators provided by the 12 frameworks discussed previously. All indicators are obtained from the different layers, following the detection of overlapping or replication attributes. All indicators that are not related to water supply systems, such as stormwater or wastewater, are eliminated. The final output will determine the foundation for developing a robust resilience indicator bank for WSSs. Figure 3 shows the selected global performance indicator systems systematically reviewed and then funnelled into the indicator bank. The total number of 534 indicators pooled is filtered by removing similar and duplicated indicators, leaving 216 indicators available in the new bank. The study then identifies the structure of the proposed indicator systems. The indicators will be categorised based on the proposed system.

\section{Proposed Structure of Indicators}

After understanding and analysing each indicator derived from the pool of indicators and before structuring the proposed indicator bank, a typical framework must be described. Each code utilised a different classification system and specific categorisation (refer to Figure 2). A framework of indicators for the WSSs' resilience must represent the policy, processes, and strength to measure its performance. The foundation of those indicators should ideally be based on a series of primary criteria. These indicators should be specific [37, 45], consider simplicity [34, 37, 45, 80-82], transparency [34, 45, 80-82], objectivity $[28,37]$, sensitivity $[28,37,81]$, and be distinctive. A brief description of these criteria is presented as follows:

(i) Specific: the indicator should be appropriate and relevant

(ii) Simplicity: the indicator should be understandable for decision-makers and experts

(iii) Transparency: it should be possible for other people to recreate and check indicators

(iv) Objectivity: whether the indicator can be used over time based on updated and reproduced data

(v) Sensitivity: whether the indicator reflects changes in the situation

(vi) Distinctive: the indicator lacks redundancy and does not measure something already captured under other indicators

Other researchers define other criteria that are a proxy of provided criteria or inappropriate in this study. Affordability, for example, refers to the fact that data can be collected at a reasonable cost, resources, and time $[34,45,82]$ or availability which refers that easy access to the data is eliminated since the 


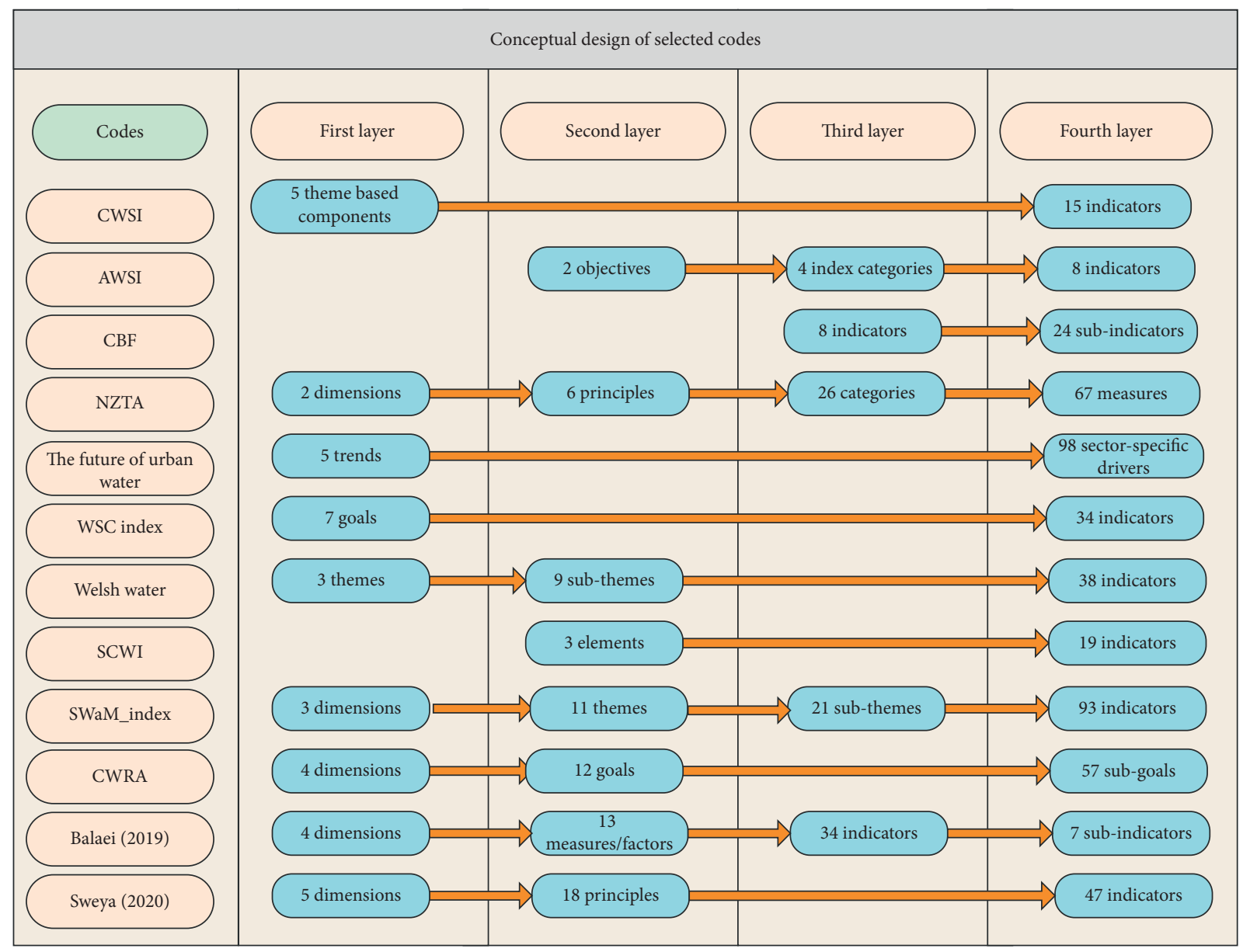

FIgURE 2: Conceptual design of selected codes.

purpose of this study is to take into account the most valuable indicators irrespective of data concerns.

The indicator sets are gathered from the twelve codes previously created. The structure of the proposed indicator bank is classified into three layers here. The first layer is named dimension which maintains a sector-based approach in line with characteristics developed by $[3,51,68,73,74]$. Next, WSSs' performance is measured at the attributes level, reflecting a problem-based approach in which the main issues of WSSs' resilience that belongs to the sector, as mentioned earlier, are addressed. Indicators are the third and final level measurement to determine the essential characteristics of water supply system resilience. Figure 4 shows the overall view of the proposed system.

The multidimensional idea of calculating resilience was first identified by [22]. The four dimensions of Bruneau et al. [22] include technical, organisational, social, and economic (TOSE) to measure the resilience of communities. Many other researchers modified or expanded this work to create a framework to measure the system's performance based on their requirements. For example, the ecological dimension is added by Vugrin et al. [83] to measure the resilience of eight separate systems. Hughes and Healy used organisational and technical dimensions to measure the transportation system's resilience. The environmental dimension is described and added by Balaei [3] and Vugrin et al. [83], and later on, the indicators of this dimension are proposed and applied by Sweya and Wilkinson [42] to measure the resilience of the water supply system in Tanzania. However, the authors added smartness and advanced technology dimension to present indicators relevant to this dimension.

The same approach is used to create attributes for each dimension. In the technical dimension, for example, the robustness and redundancy attributes come from $[4,44,68]$, safeto-fail attribute is extracted from $[44,68]$, and flexibility attribute is extracted from [44]. After detecting overlapped or replicated indicators, all the indicators are analysed and categorised for the last layer in the related attribute and dimensions. The study's scope is the collection of indicator bank of WSSs, so the indicators that did not belong to this have been removed. All dimensions, attributes, and indicators are analysed and categorised independently. This approach can help to measure the resilience of the system by each dimension or attributes independently. The overall performance of the system as a whole also can be measured by integrating each dimension.

\section{Comprehensive Indicator Bank for the Resilience of Water Supply Systems}

The proposed indicator bank comprises six dimensions, 27 attributes, and 216 indicators. The water supply systems' resilience indicator bank is presented in Table 2 . 


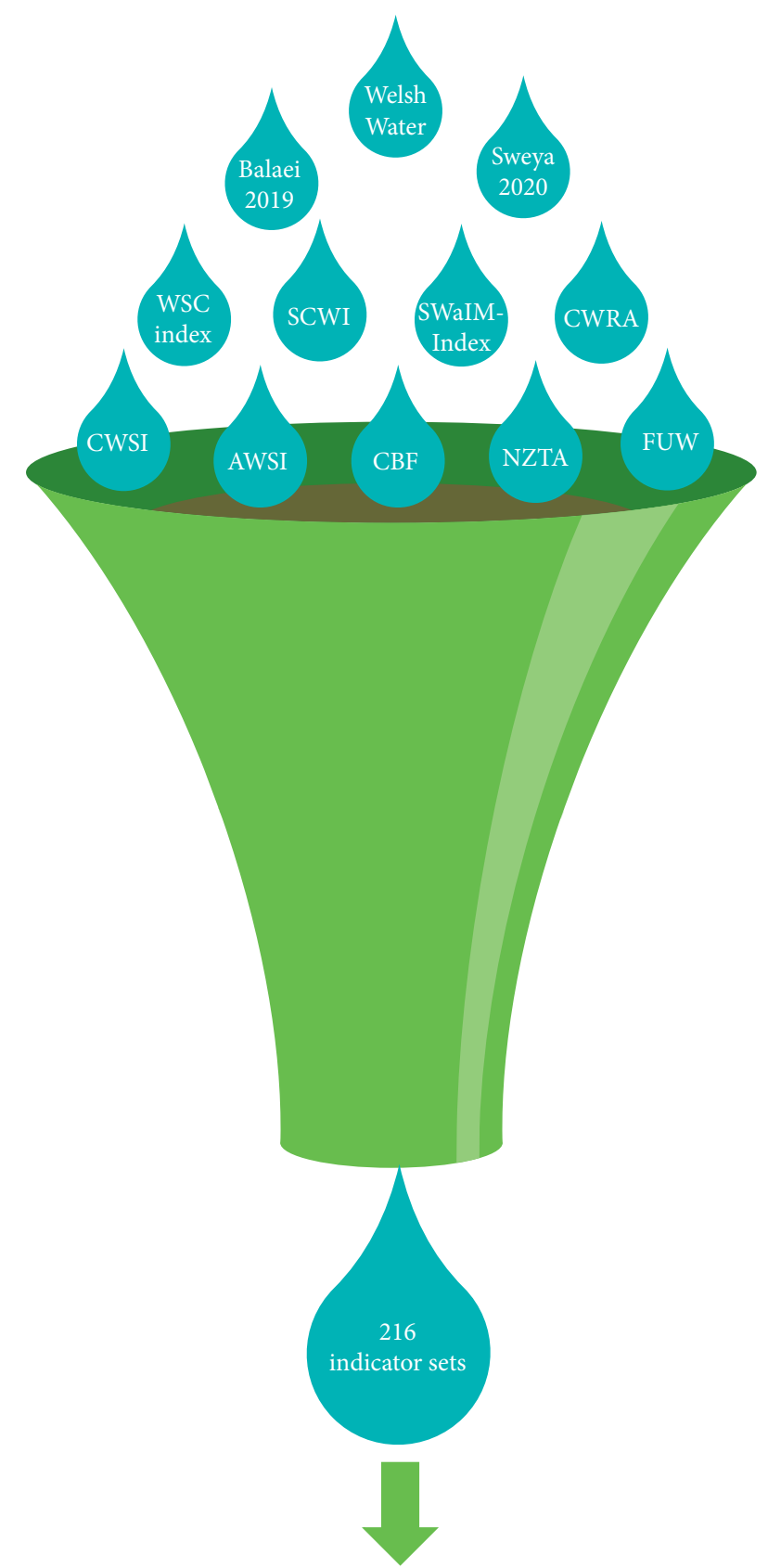

New Comprehensive Indiator Bank

Figure 3: Indicator pool of selected codes to build a new robust indicator bank.

Technical dimension refers to the ability of a system's physical elements to operate at an acceptable level after a catastrophe $[4,22,84]$. The technical dimension comprises four attributes: robustness, redundancy, flexibility, and safe-to-fail. The technical dimension totally has 49 indicators. For example, interdependency belongs to the robustness attributes and refers to the degree of water supply system dependency to other lifeline systems such as power systems in pump stations.

The organisational dimension refers to the capacity of organisations to help communities in disaster preparedness, response, and recovery [45]. The organisational dimension has four attributes and 61 indicators. Change readiness, network and relationship, functioning as a unified team, effective leadership, and governance and strategy are the attributes of the organisational dimension. For instance, the mutual aid and assistance indicator belongs to change readiness attributes. The application of this indicator is when a water company does not have the capacity to provide all equipment/spare parts or facilities in a disaster. Therefore, a mutual aid agreement can be signed between the companies to support water companies in emergencies, for example, an agreement between the water company and power company to provide electricity in pump stations.

The resources rooted in ones' social network that can be accessed or developed by bonds and interaction within these networks are referred to as social capital $[85,86]$. The social dimension comprises nine attributes and 42 indicators. The attributes of social dimensions include education, preparedness, social structure, human health and wellbeing, public participation, togetherness, equity of essential services, violence rate, and trust. For example, community capacity belongs to the preparedness attribute and refers to communities' capacity to prepare for and respond to extreme disasters.

Economic resilience is categorised into static and dynamic resilience, according to Rose [87]. The static term refers to the effective utilisation of resources at a given time, while the dynamic term refers to economic repair and restoration that influences the economy's time path [43]. The economic dimension has one attribute and 18 indicators. For example, quick access to finance is recognised as an indicator that can be applied in the restoration and recovery phase when the damage occurs to water supply systems' assets.

Environmental resilience aligns with ecological resilience, which refers to the adaptation and adjustment of a system in response to changing environment [42]. Environmental resilience is classified into five attributes and 30 indicators. Ecosystem health, ecosystem health, climate change policy, debris management, and delivering sustainable energy and resources are the attributes of environmental resilience. Protection of groundwater and surface water resources is an indicator of improving ecosystem health attributes.

Smart water systems are part of the larger group of cyber-physical systems which combine physical and software elements to perform data processing, system control, and automated decision-making autonomously or simultaneously [88]. Smartness and advanced technologies dimension is categorised into four attributes and 17 indicators. Information technologies, communication systems, advanced tools, and smart materials are the attributes of this dimension. The application of early warning systems is an example of utilising smart infrastructure as an indicator.

The proposed comprehensive indicator bank is extracted from twelve codes. The water companies can utilise all indicators as a whole package to measure the resilience of their system in all six proposed dimensions, or 


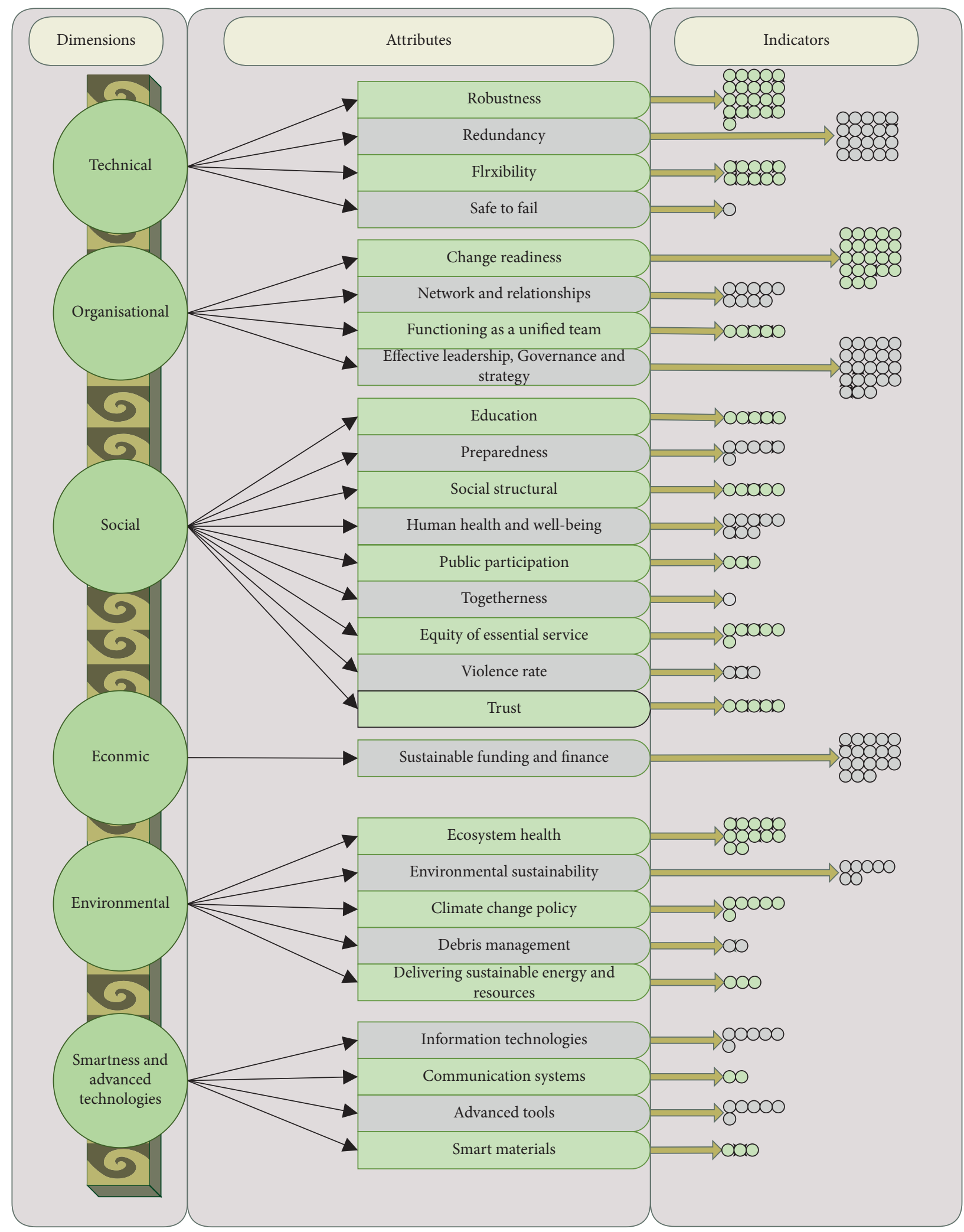

FIGURE 4: Structure of proposed indicator bank for the resilience of water supply systems.

it can be used to measure only one dimension or only one attribute. However, the proposed indicators bank is comprehensive; it needs to be finalised with experts within water companies to select their suitable indicators. For example, some companies may be interested in measuring only one dimension rather than in all dimensions. Moreover, the indicators set may vary in different locations and for various disasters. 


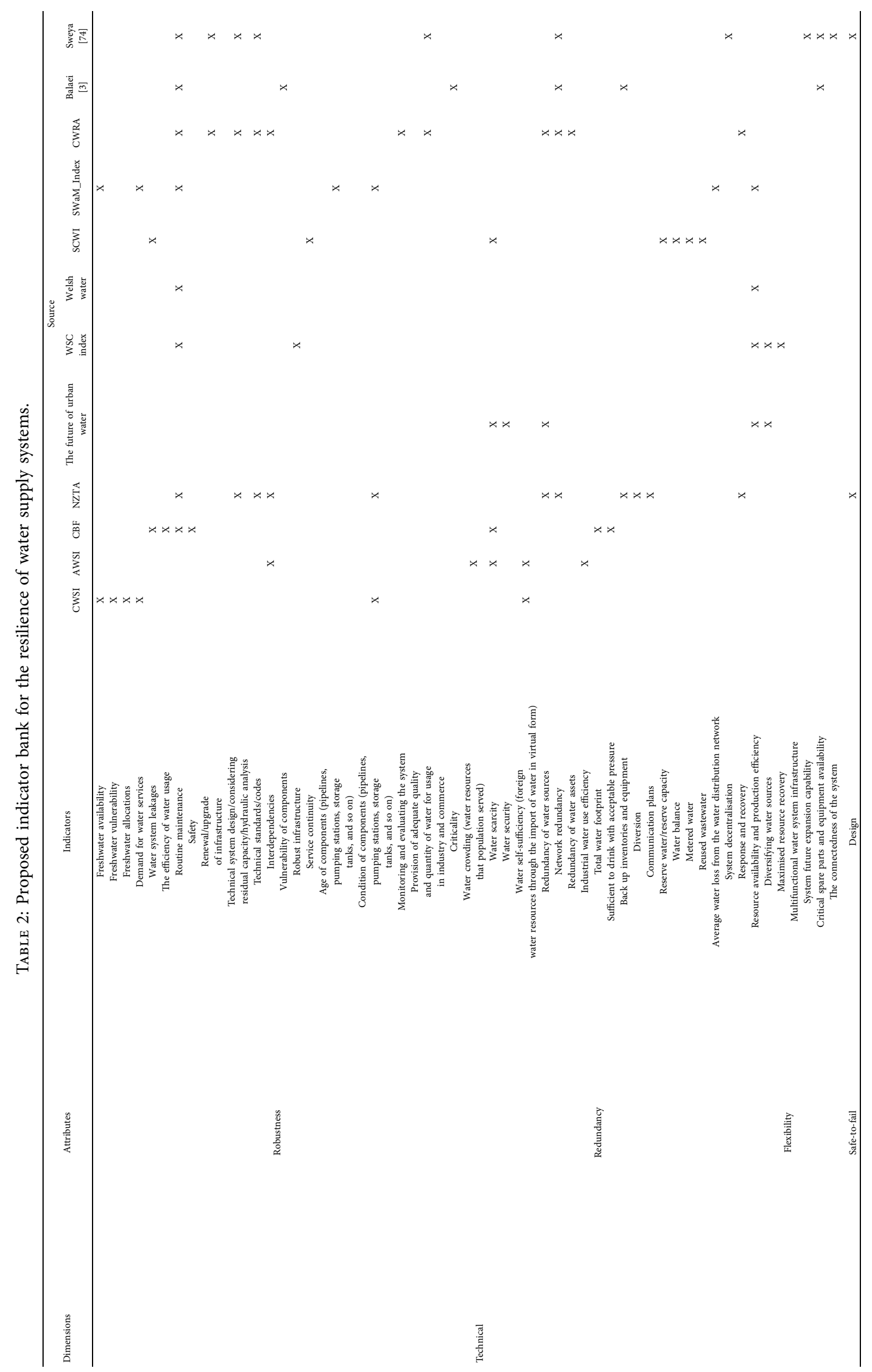


12

Advances in Civil Engineering

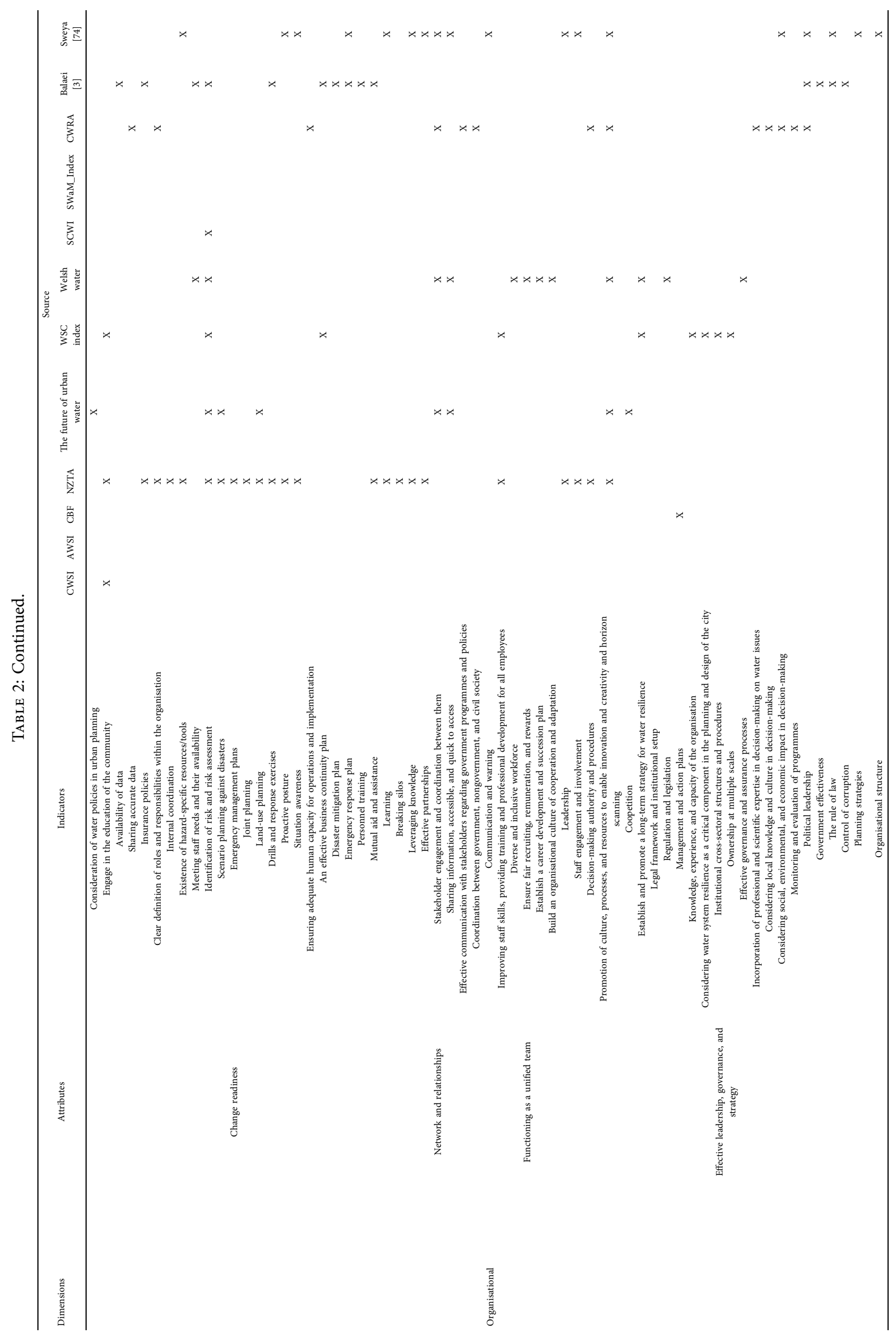




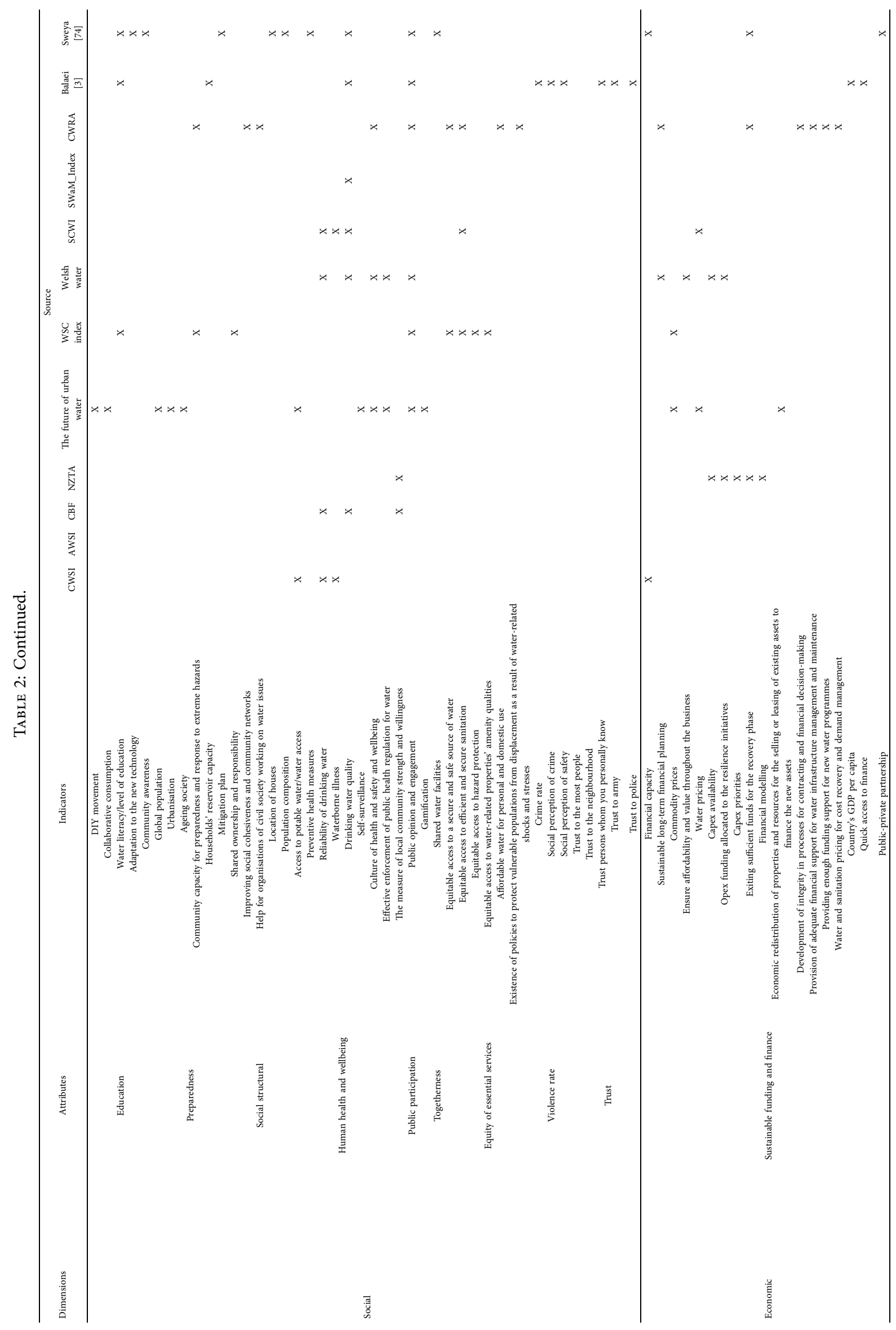




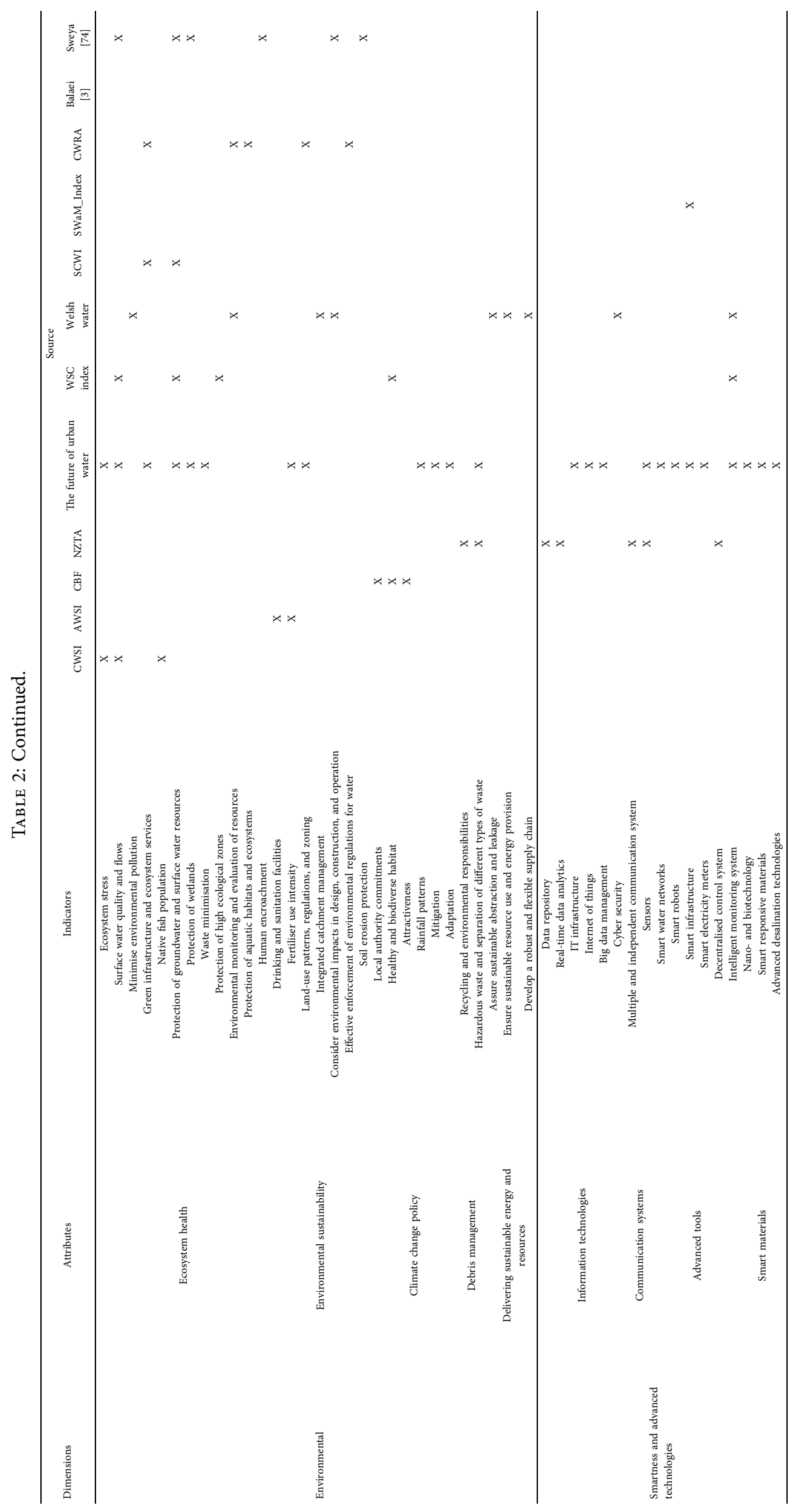




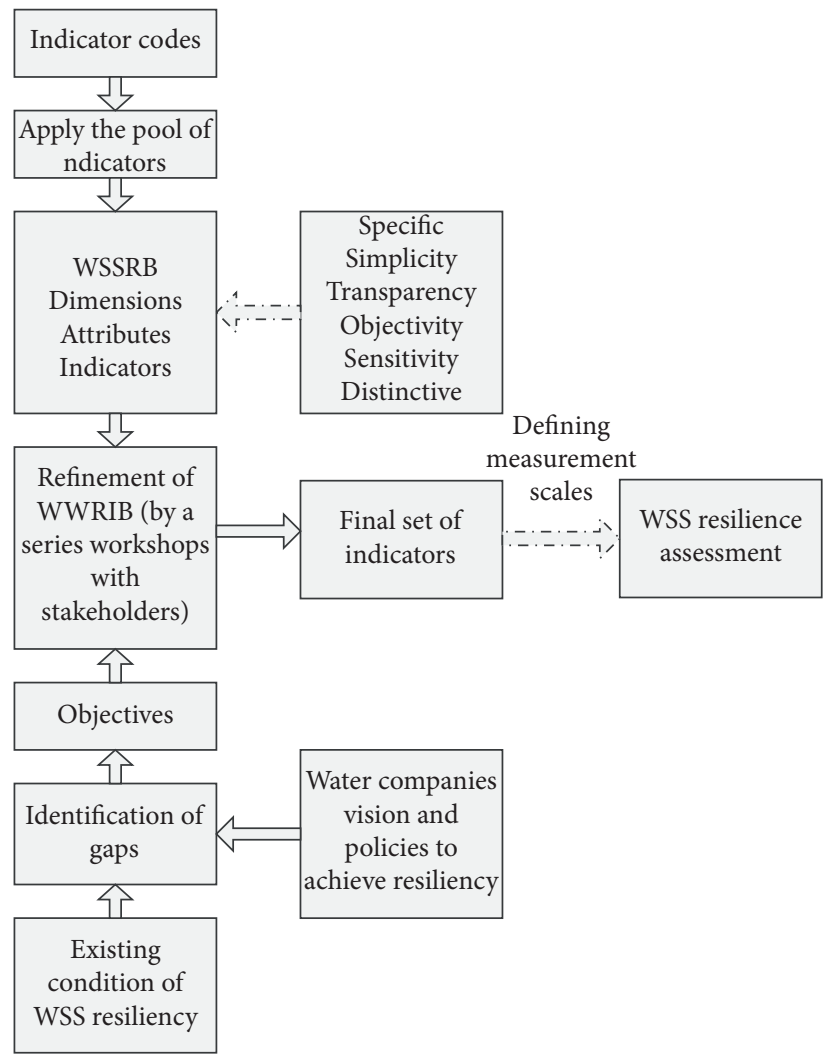

Figure 5: Application of the proposed indicator bank.

\section{Discussion}

This section describes how the proposed indicators bank can be applied in a case. The appropriate indicators need to be selected before measuring the resilience of a water supply system. More details are provided in the following subsections.

8.1. Selecting Appropriate Indicators for a Specific Water Supply System. A combination of top-down and bottom-up approaches [50] is needed to finalise the indicators. The proposed indicator bank is developed for global usage and is applicable to different disasters. However, it is essential to pick the appropriate indicators from the comprehensive indicator banks as the indicators differ by scale (local, regional, and others), location, and company vision and policy. A water corporation, for instance, may not be interested in improving the smartness of its system according to the size and budget, which will influence the final collection of indicators that they may need to work on to improve its water resiliency standards. Similarly, a company may be only interested in improving its system's resilience according to a specific disaster. In this case, some indicators may need to be added or removed from the indicators bank to develop relevant indicators for a particular disaster that the company is addressing. For example, buried assets may affect differently in the face of flooding compared with earthquakes.

Therefore, a company needs to review its specific vision and policies, look at the existing resilience situation, identify the gaps, and set the company goals. The set of indicators needed for a particular resiliency target should be refined through a series of workshops with relevant experts and then finalised. Figure 5 shows the top-down and bottom-up approaches to finalise the suitable indicators for a specific company.

8.2. Measuring the Resilience of a System. The proposed indicator banks intend to measure the resilience of a system. Therefore, a series of measurement scales are required for each indicator to measure resilience. Each indicator includes some criteria which can represent its performance level. There are various types of variables with distinct scales to measure resilience. To illustrate, some indicators are Boolean data types that only have two possible values (true or false), while some indicators can be measured by percentage, and others can be measured by per capita. For the combination of these values, a scaling process is necessary. Otherwise, the Likert scale can be developed for each indicator where the higher rank shows a higher level of resilience.

However, the result of the ranking does not show the absolute value for each indicator since each dimension/attribute/indictor's weight needs to be considered alongside these ranks. It is critical to assign weights to variables, so it helps the user to decide which variables are more significant than others. Various methods are available for extracting the weights of attributes/indicators [89]. Mayunga [10] for assigning weight to variables; identified five different approaches for the analysis, measurement, and mapping of 
community disaster resilience. One or a combination of the above approaches can be applied to generate the weight of each dimension/attribute/indictor.

The overall resilience of a water supply system will be an index driven by aggregating the weighted values of each dimension/attribute/indicator across the ranking of each indicator.

The resilience measuring can be designed based on benchmarking or baseline assessment. Benchmarking assessment approach is being used to compare a system's resilience with its peers, for example, the resilience of a city's water supply system to be compared with that of another city. The baseline or longitudinal assessment approach is being used to compare the performance of a system over time. The baseline provides a point of reference for measuring the improvement of a system over time [29] by way of illustration, tracking, and comparing changes in the resilience of a water supply system over time.

The water supply systems are critical infrastructures that are dependent on other lifelines like power systems. For example, pump stations are highly dependent on electricity. Therefore, the performance of water supply systems is not only dependent on its own system but also on other systems. The paper is recommended that these indicators should be tested in a water company to measure the level of its dependency. However, in the result section, these indicators have been proposed, such as "interdependencies" and "Mutual aid and assistance." Interdependencies refer to the dependency of WSSs to other lifelines such as power, transportation, and communication systems, and mutual aid and assistance refer to the agreement between the different companies to support water companies in emergencies. For example, an agreement should be signed between the water and power companies to provide electricity in pump stations after disasters.

\section{Conclusion}

The WSSs are consistently at risk from natural disasters. Compared with conventional methods such as risk analysis, the range of disasters and their adverse effects on WSSs has prompted water companies and decision-makers worldwide to look for alternatives to assess WSSs' performance against disasters. The WSSs' performance against disasters can be improved through the resilience concept. The indicatorbased approach is developed to measure the performance of the WSSs for future disasters. Nonetheless, finding suitable indicators to measure system performance remains a challenge for water companies and decision-makers. Therefore, this paper targets a more comprehensive indicator bank to envision a groundwork solution towards the WSSs' resilience. The proposed indicator bank provides a foundation for water companies and decision-makers to improve their resiliency.

Due to WSSs' complexity, many indicators exist worldwide to measure the system's resilience. With the complexity of the WSSs' dependencies with other networks such as transport, examining the entire array of available resources to resolve resiliency may overwhelm this paper's necessary theoretical exploration. Addressing this complexity naturally constricted the research to contextualise a smaller pool of references. Therefore, twelve indicator codes are then referenced, chosen from international, national, and individual bodies. To achieve its initial aim, it interprets the chosen indicators into a more comprehensive framework by filtering all the frameworks' data, as detailed in Table 2.

The proposed comprehensive indicators bank comprises three layers: dimensions, attributes, and indicators. Totally, 216 indicators are proposed within 27 attributes and six dimensions. The water companies may use all or a part of the proposed indicators to select suitable indicators based on their needs. Therefore, the indicators need to be finalised according to the requirements of a specific company. A framework is presented to navigate this process with topdown and bottom-up approaches. After finalising the indicators, the resilience of a system can be measured by ranking the measurement scales, weighing the dimension/ attributes/indicators based on their importance, and aggregating the data. Benchmarking or baseline assessment approaches can be developed when measuring the resilience of a system.

Finally, the proposed indicator system needs to be measured in an existing WSS. Further research may be conducted in a practical case study. A revision may occur mainly since the WSSs exist within the urban systems' complexity and challenge the desired outcomes from its theoretical approach. Despite this apparent limitation, it offers more research possibilities as each case study must address various issues, which adds value to the indicator bank database towards refinement.

\section{Data Availability}

All data, models, and codes generated or used during the study are included in the published article.

\section{Conflicts of Interest}

The authors declare that there are no conflicts of interest.

\section{References}

[1] U. UNISDR, Sendai Framework for Disaster Risk Reduction 2015-2030, United Nations International Strategy for Disaster Reduction, Geneva, Switzerland, 2015.

[2] Ministry of Health, Annual Report on Drinking-Water Quality 2010-2011, Ministry of Health, Wellington, New Zealand, 2012.

[3] B. Balaei, Investigating Multidimensional Factors Affecting Water Supply Resilience to Disasters, The University of Auckland: Civil and Environmental Engineering, Auckland, New Zealand, 2019.

[4] B. Balaei, S. Wilkinson, R. Potangaroa, and P. McFarlane, "Investigating the technical dimension of water supply resilience to disasters," Sustainable Cities and Society, vol. 56, Article ID 102077, 2020.

[5] R. DesRoches, M. Comerio, M. Eberhard, W. Mooney, and G. J. Rix, "Overview of the 2010 Haiti earthquake," Earthquake Spectra, vol. 27, no. S1, pp. S1-S21, 2011. 
[6] D. B. Ballantyne and C. Crouse, Reliability and Restoration of Water Supply Systems for Fire Suppression and Drinking Following Earthquakes, US Department of Commerce, National Institute of Standards and Technology, Gaithersburg, MD, USA, 1997.

[7] S. D. Guikema, "Natural disaster risk analysis for critical infrastructure systems: an approach based on statistical learning theory," Reliability Engineering \& System Safety, vol. 94, no. 4, pp. 855-860, 2009.

[8] M. L. Carreño, O. D. Cardona, and A. H. Barbat, "A disaster risk management performance index," Natural Hazards, vol. 41, no. 1, pp. 1-20, 2007.

[9] S. B. Manyena, "The concept of resilience revisited," Disasters, vol. 30, no. 4, pp. 434-450, 2006.

[10] J. S. Mayunga, "Understanding and applying the concept of community disaster resilience: a capital-based approach," Summer Academy for Social Vulnerability and Resilience Building, vol. 1, no. 1, pp. 1-16, 2007.

[11] C. Chen, L. Xu, D. Zhao, T. Xu, and P. Lei, "A new model for describing the urban resilience considering adaptability, resistance and recovery," Safety Science, vol. 128, Article ID 104756, 2020.

[12] C. S. Holling, "Resilience and stability of ecological systems," Annual Review of Ecology and Systematics, vol. 4, no. 1, pp. 1-23, 1973.

[13] C. Folke, "Resilience: the emergence of a perspective for social-ecological systems analyses," Global Environmental Change, vol. 16, no. 3, pp. 253-267, 2006.

[14] B. Walker, C. S. Holling, S. Carpenter, and A. J. E. Kinzig, "Resilience, adaptability and transformability in social-ecological systems," Ecology and Society, vol. 9, no. 2, 2004.

[15] K. Foster, Resilience Capacity Index-Site-Resilience Capacity Index, University of California, Berkeley, CA, USA, 2012.

[16] G. P. Cimellaro, "Resilience indicators," in Urban Resilience for Emergency Response and Recovery, pp. 49-69, Springer, New York, NY, USA, 2016.

[17] J. W. Reich, "Three psychological principles of resilience in natural disasters," Disaster Prevention and Management: International Journal, vol. 15, no. 5, pp. 793-798, 2006.

[18] D. Weiss, T. Kötter, and A. Asadzadeh, "Stress testing cities-how to live and plan with new risks," in Proceedings of the IDRC DAVOS 2016 "Integrative Risk Management-Towards Resilient Cities”, pp. 360-363, Bonn, Germany, August 2016.

[19] P. Lu and D. Stead, "Understanding the notion of resilience in spatial planning: a case study of Rotterdam, The Netherlands," Cities, vol. 35, pp. 200-212, 2013.

[20] S. Y. Ponomarov and M. C. Holcomb, "Understanding the concept of supply chain resilience," International Journal of Logistics Management, vol. 20, no. 1, pp. 124-143, 2009.

[21] A. M. Madni and S. Jackson, "Towards a conceptual framework for resilience engineering," IEEE Systems Journal, vol. 3, no. 2, pp. 181-191, 2009.

[22] M. Bruneau, S. E. Chang, R. T. Eguchi et al., "A framework to quantitatively assess and enhance the seismic resilience of communities," Earthquake Spectra, vol. 19, no. 4, pp. 733-752, 2003.

[23] D. Rehak, P. Senovsky, M. Hromada, and T. Lovecek, "Complex approach to assessing resilience of critical infrastructure elements," International Journal of Critical Infrastructure Protection, vol. 25, pp. 125-138, 2019.

[24] R. Alliance, "Urban resilience research prospectus," A Resilience Alliance Initiative for Transitioning Urban Systems towards Sustainable Futures, CSIRO/Arizona State University/ Stockholm University, Australia/USA/Sweden, 2007.
[25] W. Xu, L. Xiang, D. Proverbs, and S. Xiong, "The influence of COVID-19 on community disaster resilience," International Journal of Environmental Research and Public Health, vol. 18, no. 1, p. $88,2021$.

[26] B. Mayer, "A review of the literature on community resilience and disaster recovery," Current environmental health reports, vol. 6, no. 3, pp. 167-173, 2019.

[27] C. A. Davis, "Understanding functionality and operability for infrastructure system resilience," Natural Hazards Review, vol. 22, no. 1, Article ID 06020005, 2021.

[28] H. Hahn, "Indicators and other instruments for local risk management for communities and local governments," 2003.

[29] S. L. Cutter, L. Barnes, M. Berry et al., "A place-based model for understanding community resilience to natural disasters," Global Environmental Change, vol. 18, no. 4, pp. 598-606, 2008.

[30] S. L. Cutter, C. G. Burton, and C. T. Emrich, "Disaster resilience indicators for benchmarking baseline conditions," Journal of Homeland Security and Emergency Management, vol. 7, no. 1, 2010.

[31] M. C. d. M. Martins, A. N. Rodrigues da Silva, and N. Pinto, "An indicator-based methodology for assessing resilience in urban mobility," Transportation Research Part D: Transport and Environment, vol. 77, pp. 352-363, 2019.

[32] R. DasGupta and R. Shaw, "An indicator based approach to assess coastal communities' resilience against climate related disasters in Indian Sundarbans," Journal of Coastal Conservation, vol. 19, no. 1, pp. 85-101, 2015.

[33] A. Jovanović, K. Øien, and A. Choudhary, “An indicatorbased approach to assessing resilience of smart critical infrastructures," in Urban Disaster Resilience and Security, pp. 285-311, Springer, New York, NY, USA, 2018.

[34] K. M. Morley, "Evaluating resilience in the water sector: application of the utility resilience index (URI)," 2012.

[35] S. Baki, E. Rozos, and C. Makropoulos, "Designing water demand management schemes using a socio-technical modelling approach," The Science of the Total Environment, vol. 622-623, pp. 1590-1602, 2018.

[36] D. Nikolopoulos, H.-J. van Alphen, D. Vries et al., "Tackling the "new normal": a resilience assessment method applied to real-world urban water systems," Water, vol. 11, no. 2, p. 330, 2019.

[37] B. Balaei, S. Wilkinson, R. Potangaroa, N. Hassani, and M. Alavi-Shoshtari, "Developing a framework for measuring water supply resilience," Natural Hazards Review, vol. 19, no. 4, Article ID 04018013, 2018.

[38] B. Balaei, I. Noy, S. Wilkinson, and R. Potangaroa, "Economic factors affecting water supply resilience to disasters," SocioEconomic Planning Sciences, vol. 76, Article ID 100961, 2020.

[39] B. Balaei, S. Wilkinson, R. Potangaroa, C. Adamson, and M. Alavi-Shoshtari, "Social factors affecting water supply resilience to disasters," International Journal of Disaster Risk Reduction, vol. 37, Article ID 101187, 2019.

[40] B. Balaei, S. Wilkinson, and R. Potangaroa, "Social capacities in fostering water supply resilience in Vanuatu," An International Journal Disaster Prevention and Management, vol. 28, no. 5, 2019.

[41] L. N. Sweya, S. Wilkinson, J. Mayunga, A. Joseph, G. Lugomela, and J. Victor, "Development of a tool to measure resilience against floods for water supply systems in Tanzania," Journal of Management in Engineering, vol. 36, no. 4, Article ID 05020007, 2020.

[42] L. N. Sweya and S. Wilkinson, "A tool for measuring environmental resilience to floods in Tanzania water supply 
systems," Ecological Indicators, vol. 112, Article ID 106165 , 2020.

[43] L. N. Sweya and S. Wilkinson, "Tool development to measure the resilience of water supply systems in Tanzania: economic dimension," Jàmbá: Journal of Disaster Risk Studies, vol. 13, no. 1, p. 9, 2021.

[44] L. N. Sweya, S. Wilkinson, G. Kassenga, and G. Lugomela, "Development of a tool for measuring resilience of water supply systems in Tanzania: technical dimension," Journal of Water Resources Planning and Management, vol. 147, no. 2, Article ID 04020107, 2021.

[45] L. N. Sweya, S. Wilkinson, G. Kassenga, and J. Mayunga, "Developing a tool to measure the organizational resilience of Tanzania's water supply systems," Global Business Organizational Excellence, vol. 39, no. 4, 2020.

[46] L. O. Walker and K. C. Avant, Strategies for Theory Construction in Nursing, Vol. 4, Pearson/Prentice Hall, , Upper Saddle River, NJ, USA, 2005.

[47] M. Von Thenen, P. Frederiksen, H. S. Hansen, and K. S. Schiele, “A structured indicator pool to operationalize expert-based ecosystem service assessments for marine spatial planning," Ocean \& Coastal Management, vol. 187, Article ID 105071, 2020

[48] H. Khatibi, S. Wilkinson, H. Dianat, and M. Baghersad, "Indicators bank for smart and resilient cities: design of excellence," Built Environment Project and Asset Management, 2021.

[49] H. Khatibi, S. Wilkinson, H. Dianat, and M. Baghersad, "The resilient-smart city development: a literature review and novel frameworks exploration," Built Environment Project and Asset Management, vol. 11, no. 4, pp. 493-510, 2021.

[50] A. Stratigea, A. Leka, and M. Panagiotopoulou, "In search of indicators for assessing smart and sustainable cities and communities' performance," International Journal of E-Planning Research, vol. 6, no. 1, pp. 43-64, 2019.

[51] Arup and Siwi, The City Water Resilience Approach, Rockefeller Foundation, New York, NY, USA, 2019, https://www. arup.com/perspectives/city-water-resilience-approach Available from.

[52] J. Baan, "Evaluation of water resources projects on sustainable development," in Proceedings of the International Symposium on Water Resources Planning in a Changing World, Karlsruhe, Germany, June 1994.

[53] D. P. Loucks, "Quantifying trends in system sustainability," Hydrological Sciences Journal, vol. 42, no. 4, pp. 513-530, 1997.

[54] C. Sullivan, "Calculating a water poverty index," World Development, vol. 30, no. 7, pp. 1195-1210, 2002.

[55] S. De Carvalho, K. Carden, and N. Armitage, "Application of a sustainability index for integrated urban water management in Southern African cities: case study comparison-Maputo and Hermanus," WaterSA, vol. 35, no. 2, 2009.

[56] P. Gonzales and N. Ajami, "Urban water sustainability: an integrative framework for regional water management," Hydrology and Earth System Sciences Discussions, vol. 12, no. 11, pp. 11291-11329, 2015.

[57] K. A. Klise, R. Murray, and L. T. N. Walker, Systems Measures of Water Distribution System Resilience, Sandia National Lab.(SNL-NM), Albuquerque, NM, USA, 2015.

[58] H. Alegre and R. Parena, Performance Indicators for Water Supply Services, IWA publishing, London UK, 2016.

[59] H. Alegre, "Performance indicators for water supply systems," in Proceedings of the Drought Management Planning In Water Supply Systems, pp. 148-178, Springer, Valencia, Spain, December 1999.
[60] H. Haider, R. Sadiq, and S. Tesfamariam, "Performance indicators for small- and medium-sized water supply systems: a review," Environmental Reviews, vol. 22, no. 1, pp. 1-40, 2014.

[61] H. Theuretzbacher-Fritz, J. Schielein, H. Kiesl, J. Kölbl, R. Neunteufel, and R. Perfler, "Trans-national water supply benchmarking: the cross-border co-operation of the Bavarian EFFWB project and the Austrian OVGW project," Water Supply, vol. 5, no. 6, pp. 273-280, 2005.

[62] Swwa, "The Swedish water and wastewater association-description of sustainability index," 2020, https://www.svensktvatten.se/ globalassets/organisation-och-juridik/vass/hallbarhetsindex/hallb arhetsindex_beskrivning_verktyget_2020.pdf.

[63] Sdewes Center, "The Sustainable Development of Energy, Water, and Environment Systems (SDEWES)- SDEWES index," 2020, https://www.sdewes.org/sdewes_index.php.

[64] Ş. Kılkış, "Sustainable development of energy, water and environment systems index for Southeast European cities," Journal of Cleaner Production, vol. 130, pp. 222-234, 2016.

[65] Pri, Policy Research Initiative (Pri), Canadian Water Sustainability index (CWSI): Project Report, Government of Canada, Canada, 2007.

[66] H. M. Ali, "Development of Arab water sustainability index using principal component analysis," in Proceedings of the Thirteenth International Water Technology Conference IWTC13, Citeseer, Hurghada, Egypt, 2009.

[67] C. J. van Leeuwen, J. Frijns, A. van Wezel, and F. H. M. van de Ven, "City blueprints: 24 indicators to assess the sustainability of the urban water cycle," Water Resources Management, vol. 26, no. 8, pp. 2177-2197, 2012.

[68] J. Hughes and K. Healy, "measuring the resilience of transport infrastructure," 2014.

[69] Arup, "The future of urban water: scenarios for urban water utilities in 2040," 2015, https://www.arup.com/perspectives/ publications/research/section/the-future-of-urban-water.

[70] C. Chesterfield, C. Urich, L. Beck, and K. Burge, "A water sensitive cities index-benchmarking cities in developed and developing countries," in Proceedings of the International Low Impact Development Conference, Beijing, China, June 2016.

[71] Welsh Water, "PR19 resilience in the round review," 2018, https://www.arup.com/projects/welsh-water-resilience.

[72] J. Batten, "Sustainable cities water index- which cities are best placed to harness water for future success?," 2019, https://www. arcadis.com/en/global/our-perspectives/which-cities-are-bestplaced-to-harness-water-for-future-success-/.

[73] M. Maiolo and D. Pantusa, "Sustainable water management index, SWaM_Index," Cogent Engineering, vol. 6, no. 1, Article ID 1603817, 2019.

[74] L. Sweya, Improving Water Supply Systems Resilience to Floods: Developing a Measurement Tool for Tanzania, ResearchSpace, Auckland, New Zealand, 2020.

[75] Eip Water, "City blueprints - improving implementation capacities of cities and regions (AG041)," 2020, https://www. eip-water.eu/City_Blueprints.

[76] B. C. Rogers, G. Dunn, K. Hammer et al., "Water Sensitive Cities Index: a diagnostic tool to assess water sensitivity and guide management actions," Water Research, vol. 186, Article ID 116411, 2020.

[77] The Cooperative Research Centre for Water Sensitive Cities, "Water sensitive cities index-benchmarking cities against urban water indicators," 2020, https://watersensitivecities.org. au/solutions/wsc-index/.

[78] Welsh Water, "Welsh water 2050," 2018, https://corporate. dwrcymru.com/en/about-us/our-plans/water-2050. 
[79] Ofwat, "Resilience in the Round," 2017, https://www.ofwat. gov.uk/wp-content/uploads/2017/11/Monitoring-financialresilience-2017-Report.pdf.

[80] S. L. Cutter, K. D. Ash, and C. T. Emrich, "The geographies of community disaster resilience," Global Environmental Change, vol. 29, pp. 65-77, 2014.

[81] V. De León and J. Carlos, Vulnerability: A Conceptional and Methodological Review, UNU-EHS, Bonn, Germany, 2006.

[82] L. Briguglio, Methodological and practical considerations for constructing socio-economic indicators to evaluate disaster risk. BID/IDEA Programa de Indicadores para la Gestión de Riesgos, Universidad Nacional de Colombia, Manizales, Colombia, 2003.

[83] E. D. Vugrin, D. E. Warren, M. A. Ehlen, and R. C. Camphouse, "A framework for assessing the resilience of infrastructure and economic systems," in Sustainable and Resilient Critical Infrastructure Systems, pp. 77-116, Springer, New York, NY, USA, 2010.

[84] A. Pagano, I. Pluchinotta, R. Giordano, and M. Vurro, "Drinking water supply in resilient cities: n," Sustainable Cities and Society, vol. 28, pp. 435-449, 2017.

[85] N. Lin, Social Capital: A Theory of Social Structure and Action, Cambridge University Press, Cambridge UK, 2002.

[86] B. Balaei, S. Wilkinson, and R. Potangaroa, "Impact of social characteristics of communities on water supply system resilience," in Proceedings of the IPWEA New Zealand's Annual Conference, Rotorua, New Zealand, June 2018.

[87] A. Rose, "Economic resilience to natural and man-made disasters: multidisciplinary origins and contextual dimensions," Environmental Hazards, vol. 7, no. 4, pp. 383-398, 2007.

[88] D. Marchese, A. Jin, C. Fox-Lent, and I. Linkov, "Resilience for smart water systems," Journal of Water Resources Planning and Management, vol. 146, no. 1, Article ID 02519002, 2020.

[89] Oecd, Handbook on Constructing Composite Indicators: Methodology and User Guide, OECD Publication, Paris, France, 2008. 